\title{
Peculiarities of feed contamination with citrinin and ochratoxin A
}

\author{
Galina P. Kononenko*, Alexey A. Burkin \\ Mycotoxicology Laboratory, All Russian Research Institute for Veterinary Sanitation, Hygiene and Ecology, Moscow, Russia; \\ ${ }^{*}$ Corresponding Author: kononenkogp@mail.ru
}

Received 1 October 2012; revised 10 November 2012; accepted 17 December 2012

\begin{abstract}
Occurrence of citrinin and ochratoxin $A$ in different feed ingredients and compound feeds was screened by accredited methods based on the indirect competitive enzyme-linked immunosorbent assay. High frequency co-occurrence of both toxins was found in wheat grain and processed sunflower seeds. Citrinin levels exceeded those of ochratoxin A in the majority of co-contaminated feed samples, and the ratio of (1.1 - 10):1 proved to be the most frequent. A possible role of Aspergillus and Penicillium fungi in separate and simultaneous OTA and CIT occurrence in feeds is also discussed.
\end{abstract}

Keywords: Ochratoxin A; Citrinin; Immunoassay; Feeds; Cereals

\section{INTRODUCTION}

Ochratoxin A (OTA) and citrinin (CIT) have long been known as factors of mycotoxic animal nephropathy. Both toxins were detected in barley grain by Krough and Hasselager [1]. The contaminated barley was able to induce experimental nephropathy in rats and pigs. Later OTA and CIT were found in mouldy barley and rye the consumption of which caused swine nephropathy in natural conditions [2]. In 1970s the incidence rate of these nephrotoxins was first determined for barley and oat grain received from Danish pig farms [3] as well as for hay and feed wheat, oats, barley and rye in Canada [4-6]. After that various feeds were investigated for OTA and CIT occurrence in India [7].

In recent years it has been established that OTA has properties of genotoxic carcinogen while CIT acts as non-enzymatic bioactivator of OTA, that is, CIT promotes OTA-DNA adduct formation thus increasing the negative effect of OTA [8]. In this connection the investtigation of the distribution of both toxins in agricultural commodities is of particular relevance. Therefore, in this study we made a large-scale assessment of the contamination of compound feeds and several types of feed ingredients (cereal grain, processed grain and oil seeds) with OTA and CIT. The obtained data were presented as separate and simultaneous OTA and CIT occurrence values and as ratios of their levels.

\section{MATERIALS AND METHODS}

\subsection{Sample Collection}

A total of 2380 samples of 10 different feed products (wheat, barley and maize grain, wheat bran, soy-bean and sunflower seed meal and cakes, maize "gluten", compound feeds) were submitted to our Institute in 20032009 from poultry and pig farms in Russia either in connection with complaints about livestock performance or for a regular feed quality control as part of veterinary sanitation program. Wheat and barley grain originated from the central part of European Russia. Sunflower oil-seed meal and cakes as well as maize "gluten" were homemanufactured while most samples of maize grain and soy-bean oil-seed meal and cakes were imported.

\subsection{Mycotoxin Analyses}

The determination of CIT and OTA was performed by the accredited methods based on indirect enzyme-linked immunosorbent assay (ELISA) [9,10]. First, finely ground feed samples were shaken with the mixture of acetonitrile and water $(84: 16, \mathrm{v} / \mathrm{v})$ in an orbital shaker for $1-2 \mathrm{~s}$, then incubated for $14-16 \mathrm{~h}$ at room temperature and shaken again. Filtrates were diluted with buffer and subjected to indirect ELISA. The microtiter plate wells were each coated with $200 \mu \mathrm{l}$ solid phase antigen solutions. After overnight incubation at $4^{\circ} \mathrm{C}$, the plates were washed four or five times by filling each well with $300 \mu 1$ $0.05 \mathrm{M}$ phosphate-buffered saline containing $0.05 \%$ Tween 20 . Then, $100 \mu 1$ of the solutions of either toxin standard or sample extracts and $100 \mu 1$ of specific antibody solution were added together into each well and incubated for $1 \mathrm{~h}$ at room temperature. The plates were 
washed again four or five times, as already described, and $200 \mu \mathrm{l}$ of horseradish peroxidase conjugate was added. After incubation for $1 \mathrm{~h}$ at room temperature, the plates were washed again four times and $200 \mu \mathrm{l}$ of ophenylenediamine substrate solution was added. Then, incubation at room temperature in the dark for $30 \mathrm{~min}$ followed, and the reaction was terminated by adding 50 $\mu \mathrm{l}$ of $4 \mathrm{M}$ sulfuric acid with $0.1 \mathrm{M}$ sodium sulfite to each well. Absorbency was determined at $490 \mathrm{~nm}$ using Dynatech MR-250 reader (Germany). Sample results were calculated from the standard curves. The limits of detection of OTA and CIT were 4 and 10 ppb respectively. Intercomponent cross of test systems for OTA and CIT were about $0.1 \%$. Sample extracts and standards were run in duplicate. Variation coefficient did not exceed 15\%. Data was processed with the Minitab Statistical Software (version 15).

\section{RESULTS AND DISCUSSION}

Total values of toxin occurrence in compound feeds were calculated for the set of 1231 specimens and amounted to $29.0 \%$ for OTA and $12.9 \%$ for CIT. Feed ingredients which usually make the basis of such ration compositions differed in frequency of toxic contamination with OTA and CIT. These toxins were seldom detected in soy-bean oil-seed meal and cake-only in 2 and 3 specimens out of 183 examined. The number of OTApositive samples was rather similar in different kinds of grain (30 out of 318 samples of wheat, $15 / 190$ barley and $17 / 187$ maize), appeared to be higher for wheat bran $(10 / 48)$ and was the highest for maize "gluten" (27/55) and sunflower oil-seed meal and cake (79/168). The incidence rate of CIT in the same feed ingredients (with the exception of sunflower oil-seed meal and cake) was two and more times less than that of OTA. The drop in the number of CIT-positive sunflower oil-seed meal and cake samples was not so sharp (51/168). The results corresponded to the ones obtained earlier $[9,11]$.

The distribution of toxin-positive feed samples with different types of contamination (two toxins or only one) is presented in Table 1. The frequency of separate CIT occurrence was about $10 \%$ in compound feeds and in all the ingredients with the exception of "gluten" where CIT did not occur separately. OTA as a single contaminant was found in more than half $(60 \%-80 \%)$ of the samples of barley grain, maize grain, wheat bran, "gluten" and compound feeds. Meanwhile, less than half (40\%) of the samples of wheat grain and sunflower oil-seed meal and cakes were OTA-positive. These results are also confirmed by the works of other researchers. As limited surveys conducted in India indicated, about $44 \%$ and $51 \%$ samples of compound feeds and feed ingredients were CIT-positive singly and in co-occurrence with OTA [7], while OTA in different seasons was present either in $76 \%$ or in $48 \%$ of sunflower cake samples [12]. Ready-made poultry feeds in Pakistan provided about $50 \%$ of OTApositive samples [13].

The percentage of simultaneous OTA + CIT occurrence in compound feeds was high enough (27\%). OTA + CIT occurrence was also detected in half of the toxinpositive samples of sunflower oil-seed meal and cakes and in wheat grain. It could be explained by the fact that wheat grain and sunflower oil-seed meal and cakes have traditionally been used as invariable components in ration preparation in Russia. In France, too, a high percentage $(33 \%)$ of wheat samples (collected from farms in various parts of the country) were co-contaminated with OTA + CIT [8].

Table 1. Occurrence of ochratoxin A and citrinin in different kinds of feedstuffs and in compound feeds.

\begin{tabular}{|c|c|c|c|c|c|c|}
\hline \multirow{2}{*}{ Feeds } & \multirow{2}{*}{$\begin{array}{l}\text { Analyzed } \\
\text { samples, } n\end{array}$} & \multicolumn{2}{|c|}{ Positive samples, $n^{+}$} & \multicolumn{3}{|c|}{$\begin{array}{l}\text { Positive samples, } n^{+} \\
\text {with a single toxin and with both }\end{array}$} \\
\hline & & OTA & CIT & OTA & $\mathrm{OTA}+\mathrm{CIT}$ & CIT \\
\hline Wheat grain & 318 & 30 & 19 & 14 & 16 & 3 \\
\hline Barley grain & 190 & 15 & 6 & 10 & 5 & 1 \\
\hline Maize grain & 187 & 17 & 7 & 12 & 5 & 2 \\
\hline Wheat bran & 48 & 10 & 2 & 9 & 1 & 1 \\
\hline Maize "gluten" & 55 & 27 & 10 & 17 & 10 & 0 \\
\hline Soy-bean oil-seed meal and cake & 183 & 2 & 3 & 1 & 1 & 2 \\
\hline Sunflower oil-seed meal and cake & 168 & 79 & 51 & 34 & 45 & 6 \\
\hline Compound feeds & 1231 & 357 & 159 & 246 & 111 & 48 \\
\hline Total & 2380 & 537 & 257 & 343 & 194 & 63 \\
\hline
\end{tabular}


The data on the toxin levels in the samples with separate and simultaneous occurrence is summarized in Table 2. Amounts of the toxins were below $100 \mu \mathrm{g} / \mathrm{kg}$ in most of the samples with one toxin with the exception of a few samples of grain, "gluten" and compound feeds. In all the cases of joint toxin presence in grain and sunflower oil-seed meal and cakes the toxin accumulation was higher and in several cases reached $1000 \mu \mathrm{g} / \mathrm{kg}$.

In samples with simultaneous toxin occurrence equal amounts of toxins $(4 / 194,2.1 \%)$ and predominance of OTA $(17 / 194,8.8 \%)$ were seldom found (Table 3). In wheat grain, sunflower oil-seed meal and cake, as well as in compound feeds this feature was quite distinct, possibly because on these types of feeds the fungi producing both toxins equally or with prevalence of OTA occurred very seldom. Also, it is possible that sometimes at the time of processing there can appear conditions promoting equilibrium biosynthesis of toxins or a shift towards the accumulation of OTA. Therefore, in OTA-positive grain products with a larger ratio of the outer layers of the grain kernel low concentrations of CIT are detected rather frequently [14].

In the absolute majority of samples $(173 / 194,89.1 \%)$ CIT amounts were higher than those of OTA. In two samples of this group the ratio of abundance (the ratio of CIT amount to OTA amount) was in marked contrast to the rest and amounted to 92.5 (compound feed) and 113.3 (sunflower meal). In all the other 171 samples CIT levels were 1.1 - 33.0 times higher than those of OTA with the predominance of samples with 1.1 - 10 times abundance (Figure 1). This range was typical of the most samples of wheat grain, sunflower oil-seed meal and cake as well as of compound feeds. In all the samples of barley, maize grain and "gluten" and wheat bran with simultaneous toxin occurrence and CIT prevalence the ratio of CIT/OTA levels did not exceed 10 times.

For comparison: the relation of OTA and CIT amounts in one geese feed sample equalled 4 [15], while CIT lev-

Table 2. Levels of OTA and CIT in different kinds of feedstuffs and compound feeds with separate and simultaneous toxin occurrence.

\begin{tabular}{|c|c|c|c|c|}
\hline \multirow{3}{*}{ Feeds } & \multicolumn{4}{|c|}{ Level of toxins, $\mu \mathrm{g} / \mathrm{kg}$, in the samples } \\
\hline & \multicolumn{2}{|c|}{ With separate toxin occurrence } & \multicolumn{2}{|c|}{ With simultaneous toxin occurrence } \\
\hline & OTA & CIT & OTA & CIT \\
\hline Wheat grain & $4-55$ & $79 ; 173 ; 175$ & $6-270$ & $20-1000$ \\
\hline Barley grain & $4-25$ & 371 & $5-102$ & $32-998$ \\
\hline Maize grain & $5-141$ & $20 ; 22$ & $29-390$ & $25-953$ \\
\hline Wheat bran & $4-10$ & 24 & 5.6 & 50 \\
\hline Maize "gluten" & $4-126$ & 0 & $12-100$ & $16-62$ \\
\hline Soy-bean oil-seed meal and cake & 4 & $14 ; 30$ & 21 & 20 \\
\hline Sunflower oil-seed meal and cake & $4-100$ & $16-91$ & $4-186$ & $14-1020$ \\
\hline Compound feeds & $4-250$ & $12-182$ & $4-141$ & $16-740$ \\
\hline Total & $4-250$ & $12-371$ & $4-390$ & $14-1020$ \\
\hline
\end{tabular}

Table 3. Relation of OTA and CIT levels in different kinds of feedstuffs and compound feeds with simultaneous toxin occurrence.

\begin{tabular}{|c|c|c|c|c|}
\hline \multirow{2}{*}{ Feeds } & \multirow{2}{*}{$\begin{array}{c}\text { Samples with } \\
\text { simultaneous toxin } \\
\text { occurrence, } n^{+}\end{array}$} & \multicolumn{3}{|c|}{ Including samples with different ratio of toxin levels } \\
\hline & & CIT $>$ OTA & $\mathrm{CIT}=\mathrm{OTA}$ & $\mathrm{CIT}<\mathrm{OTA}$ \\
\hline Wheat grain & 16 & 15 & 0 & 1 \\
\hline Wheat bran & 1 & 1 & 0 & 0 \\
\hline Barley grain & 5 & 4 & 0 & 1 \\
\hline Maize grain & 5 & 4 & 0 & 1 \\
\hline Maize "gluten" & 10 & 5 & 0 & 5 \\
\hline Soy-bean oil-seed meal and cake & 1 & 0 & 1 & 0 \\
\hline Sunflower oil-seed meal and cake & 45 & 43 & 0 & 2 \\
\hline Compound feeds & 111 & 101 & 3 & 7 \\
\hline Total & 194 & 173 & 4 & 17 \\
\hline
\end{tabular}




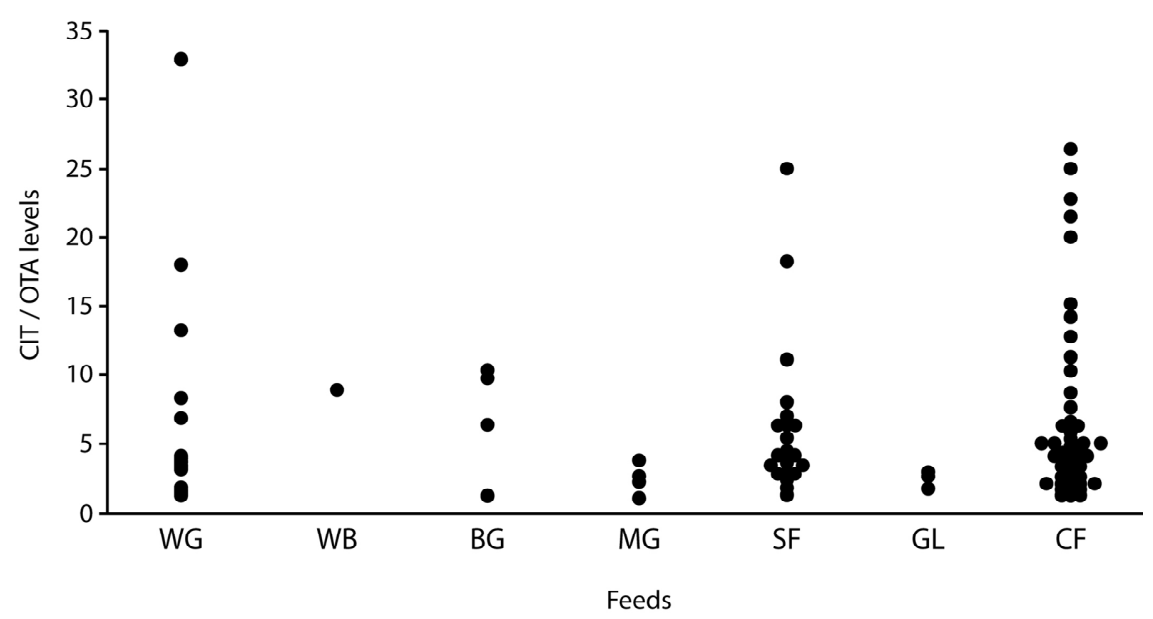

Figure 1. Ratio of CIT/OTA levels in samples of feedstuffs $[\mathrm{WG}=$ wheat grain; $\mathrm{WB}=$ wheat bran; $\mathrm{BG}=$ barley grain; $\mathrm{MG}=$ maize grain; $\mathrm{SF}=$ sunflower oil-seed meal and cake; GL = maize "gluten"] and compound feeds [CF] with simultaneous toxin occurrence when CIT levels prevail.

els in seven cereal samples with simultaneous toxin occurrence (the samples were collected in 1998 in Bulgarian villages with a history of Balkan endemic nephropathy) were 2 - 200 times higher than those of OTA [16].

Obviously the revealed differences in the character of OTA and CIT occurrence in feeds are connected with the peculiarities of feed infection with microscopic toxigenic fungi, but so far we have not been able to give any plausible interpretation of the results. A large number of fungi species belonging to the genera Aspergillus and Penicillium are able to produce OTA and CIT $[17,18]$. However, no special investigation and identification of CIT producers in feeds has been attempted in our country, and there is very limited information on taxonomy and incidence of fungal species able to produce OTA. Only 11 Aspergillus ochraceus Wilhelm isolates and 5 Penicillium viridicatum Westling isolates obtained from different kinds of feeds were reported as being capable of producing OTA [19]. Not long ago an active strain of $A$. alliaceus Thom. \& Church No. 115 was isolated from barley grain [20]. It is noteworthy that namely this species is most often considered to be a possible source of OTA in agricultural commodities [21,22].

The simultaneous occurrence of OTA and CIT in feeds is not unexpected. According to numerous scientific reports, the microscopic fungus $P$. viridicatum $[4,23-26]$ later re-identified as $P$. verrucosum $[17,27,28]$ as well as separate representatives of the species $P$. purpurrescens, P. palitans, P. cyclopium [17] are able to produce both mycotoxins. The joint production of substantial amounts of CIT and smaller amounts of OTA has recently been confirmed in our laboratory for a few strains of $P$. viridicatum Westl. isolated from the contaminated samples of feed pea (Urals, near Tiumen), from wheat grain (Yakutia) and from oat grain (European Russia, Lipetsk region) (unpublished data). According to the published data, the type of substrate and the surrounding conditions have a marked effect on the final biosynthetic profile the fungi capable of producing both toxins [24]. This, possibly, can explain significant variations in toxin ratios in feeds with simultaneous occurrence of OTA and CIT.

\section{CONCLUSION}

The data obtained in the course of this research confirm the wide incidence of OTA and CIT in feeds and especially in wheat grain, by-products of the industrial processing of maize grain, sunflower seeds and compound feeds. In most samples with joint toxin occurrence the CIT amount is 1.1 - 10 times greater than the OTA amount. The conditions of the biochemical interaction between OTA and CIT in vivo which could increase the negative effect of OTA on the human organism as well as the role of the quantitative relation between these substances will have to be cleared up in future. If CIT is able to activate OTA at equal or ten times greater concentrations, it becomes essential that the regulation for OTA in feeds with extremely high incidence rate of CIT should be revised. We hope that our data about OTA and CIT distribution in feeds will be conducive to further improvement of feed safety standards which, in its turn, will diminish the danger of animal mycotoxicoses.

\section{ACKNOWLEDGEMENTS}

The authors thank Niele Lapteikiene for excellent technical support.

\section{REFERENCES}

[1] Krough, P. and Hasselager, E. (1968) Studies on fungal nephtotoxicity. In: Royal Veterinary and Agricultural 
College Yearbook, Copenhagen, 198-214.

[2] Krough, P. (1972) Natural occurrence of ochratoxin A and citrinin in cereals associated with field outbreaks of swine nephropathy. Proceedings of IUPAC-Sponsored Symposium: Control of Mycotoxins, Gotenburg, 19.

[3] Krough, P., Hald, B. and Pedersen, E.J. (1973) Occurrence of ochratoxin A and citrinin in cereals associated with mycotoxic porcine nephropathy. Acta Pathologica et Microbiologica Scandinavica Section B, 81, 689-695.

[4] Scott, P.M., Walbeek, W., van Harwig, J. and Fennell, D.I. (1970) Occurrence of a mycotoxin, ochratoxin A, in wheat and isolation of ochratoxin A and citrinin producing strains of Penicillium viridicatum. Canadian Journal of Plant Science, 50, 583-585. doi:10.4141/cjps70-108

[5] Scott, P.M., Walbeek, W., van Kennedy, B. and Anyeti, D. (1972) Mycotoxins (ochratoxin A, citrinin, and sterigmatocystin) and toxigenic fungi in grains and other agricultural products. Agricultural and Food Chemistry, 20, 1103-1109. doi:10.1021/jf60184a010

[6] Prior, M.G. (1976) Mycotoxin determination on animal feedstuffs and tissues in Western Canada. Canadian Journal of Comparative Medicine, 40, 75-79.

[7] Ahamad, D.B. and Vairamuthu, S. (2000) Occurrence of citrinin mycotoxin in compounded feeds and various feed ingredients of poultry ration in Namakkal area (Tamil Nadu). Indian Journal of Environmental Toxicology, 10, 84-86.

[8] Pfohl-Leszkowicz, A. and Manderville, R.A. (2007) Ochratoxin A: An overview on toxicity and carcinogenicity in animals and humans. Molecular Nutrition \& Food Research, 51, 61-99. doi:10.1002/mnfr.200600137

[9] Kononenko, G.P. and Burkin, A.A. (2008) A survey on the occurrence of citrinin in feeds and their ingredients in Russia. Mycotoxin Research, 24, 3-6. doi:10.1007/BF02985263

[10] Kononenko, G.P. and Soboleva, N.A. (2004) Improvement of methods for ochratoxin A determination in feeds based on enzyme immunoassay. Russian Agricultural Sciences, 6, 23-27.

[11] Burkin, A.A., Kononenko, G.P. and Soboleva, N.A. (2005) Ochratoxin A contamination of grain feeds. Russian Agricultural Sciences, 3, 32-35.

[12] Suganthi, M.P.F., Ravi, R., Purushothaman, M.R., Monah, B. and Vasanthakumar, P. (2003) Occurrence of ochratoxin A in sunflower cake in poultry. Indian Journal of Poultry Science, 38, 37-41.

[13] Hanif, N.Q., Muhammad, N., Khatoon, S. and Malik, N. (2005) Prevalence of mycotoxins in poultry finished feed. Journal of Animal and Veterinary Advances, 4, 189-193.

[14] Meister, U. (2003) Detection of citrinin in ochratoxin Acontaining products by a new HPLC method. Mycotoxin Research, 19, 27-30. doi:10.1007/BF02940087

[15] Stahr, H.M., Domoto, M., Zhu, B.L. and Pfeiffer, R. (1985) Chemical analysis for ochratoxin poisoning. Mycotoxin Research, 1, 31-35. doi:10.1007/BF03191952
[16] Vrabcheva, T., Usleber, E., Dietrich, R. and Martlbauer, E. (2000) Co-occurrence of ochratoxin A and citrinin in cereals from Bulgarian villages with a history of Balkan endemic nephropathy. Journal of Agricultural and Food Chemistry, 48, 2483-2488. doi:10.1021/jf990891y

[17] Frank, H.K. (1992) Citrinin. Zeitschrift fur Ernahrungswissenschaft, 31, 164-177. doi:10.1007/BF01611139

[18] Varga, J., Rigo, K., Teren, J. and Mesterhazy, A. (2001) Recent advances in ochratoxin research I. Production, detection and occurrence of ochratoxins. Cereal Research Communications, 29, 85-92.

[19] Eroshkin, A.A., Soboleva, N.A., Burkin, A.A. and Kononenko, G.P. (2000) Ochratoxin A producers in grain feeds. Problemy veterinarnoi sanitarii i ekologii. Sbornik nauchnych trudov, 109, 134-144.

[20] Vasyl'ev, D.A., Piryazeva, E.A. and Soboleva, N.A. (2009) A high active producer of ochratoxin A from forage grain. Veterinarnaya Patologiya, 30, 72-75.

[21] Bayman, P., Baker, J.L., Doster, M.A., Michailides, T.J. and Mahoney, N.E. (2002) Ochratoxin production by the Aspergillus ochraceus Group and Aspergillus alliaceus. Applied and Environmental Microbiology, 68, 2326-2329. doi:10.1128/AEM.68.5.2326-2329.2002

[22] Czerwiecki, L., Czajkowska, D. and Witkowska-Gwiazdowska, A. (2002) On ochratoxin A and fungal flora in polish cereals from conventional and ecological farms. Part I. Occurrence of ochratoxin A and fungi in cereals in 1997. Food Additives and Contaminants, 19, 470-477. doi:10.1080/02652030110113726

[23] Boley, A. and Muller, H.M. (1986) Production of ochratoxin A, citrinin and ergosterol by Penicillium viridicatum in autoclaved and non-autoclaved wheat at low temperature. Mycotoxin Research, 2, 99-103. doi:10.1007/BF03191970

[24] Harwig, J. and Chen, Y.K. (1974) Some conditions favoring production of ochratoxin A and citrinin by Penicillium viridicatum in wheat and barley. Canadian Journal of Plant Science, 54, 17-22. doi:10.4141/cjps74-003

[25] Krough, P. (1973) Nephropathy caused by mycotoxins from Penicillium and Aspergillus. Journal of Genetics and Microbiology, 73, 34-35.

[26] Krough, P., Hasselager, E. and Friis, P. (1970) Studies on fungal nephrotoxicity. II. Isolation of 2 nephrotoxic compounds from Penicillium viridicatum West: Citrinin and oxalic acid. Acta Pathologica et Microbiologica Scandinavica Section $B$, 78, 401-413.

[27] Pitt, J.I. (1987) Penicillium viridicatum, Penicillium verrucosum, and production of ochratoxin A. Applied and Environmental Microbiology, 53, 266-269.

[28] Scudamore, K.A., Clarke, J.H. and Hetmanski, M.T. (1993) Isolation of Penicillium strains producing ochratoxin A, citrinin, xanthomegnin, viomellein and vioxanthin from stored cereal grains. Letters in Applied Microbiology, 17, 82-87.

doi:10.1111/j.1472-765X.1993.tb00377.x 